Research Article

\title{
Numerical Study on the Denitrification Efficiency of Selective Noncatalytic Reduction Technology in Decomposing Furnace
}

\author{
Shunsheng Xu, ${ }^{1,2}$ Jiazhen He $\mathbb{D}^{1}{ }^{1}$ Fei Pei, ${ }^{1}$ Kun Li, ${ }^{1}$ Lele Liu, ${ }^{1}$ and Zhiyong Dai ${ }^{1}$ \\ ${ }^{1}$ School of Mechanical Engineering, Xiangtan University, Xiangtan 411105, China \\ ${ }^{2}$ School of Energy Science and Engineering, Central South University, Changsha 410083, China \\ Correspondence should be addressed to Jiazhen He; 1356088529@qq.com
}

Received 13 January 2020; Revised 27 May 2020; Accepted 8 June 2020; Published 9 July 2020

Guest Editor: Yanqing Niu

Copyright (C) 2020 Shunsheng Xu et al. This is an open access article distributed under the Creative Commons Attribution License, which permits unrestricted use, distribution, and reproduction in any medium, provided the original work is properly cited.

In order to reduce the nitrogen oxide emission of cement plant, the denitrification of decomposing furnace is studied in this paper. Based on Fluent software platform, the $2500 \mathrm{t} / \mathrm{d}$ new dry-process cement kiln decomposing furnace of a plant is modeled and simulated by using air fractional combustion technology combined with selective noncatalytic reduction technology. The model and simulation methods are verified by the field test. The effects of the urea injection position and ammonia-nitrogen molar ratio on $\mathrm{NO}, \mathrm{NH}_{3}$, and denitrification efficiency are studied by numerical simulation. The results show that the optimal injection position of the urea solution is $12 \mathrm{~m}$, the optimal ammonia/nitrogen molar ratio is 1.8 , and the optimal injection velocity of the urea solution is $40 \mathrm{~m} / \mathrm{s}$. The simulation results obtained under the optimal parameters are as follows: NO concentration is $187.60 \mathrm{mg} / \mathrm{m}^{3}, \mathrm{NH}_{3}$ escape is $32.40 \mathrm{mg} / \mathrm{m}^{3}$, and denitrification efficiency is $74.75 \%$.

\section{Introduction}

Cement industry is the third largest source of $\mathrm{NO}_{\mathrm{x}}$ pollution in China [1], and the resulting $\mathrm{NO}_{\mathrm{x}}$ can cause environmental problems such as acid rain and photochemical smog $[2,3]$, so it is urgent to carry out energy-saving and emission reduction technology transformation. At present, $\mathrm{NO}_{\mathrm{x}}$ emission reduction technologies mainly include low $\mathrm{NO}_{\mathrm{x}}$ burners, fractional combustion (fuel classification or air classification), selective catalytic reduction (SCR), and selective noncatalytic reduction (SNCR) [4]. SCR denitrification technology is highly efficient, but it is expensive and complicated, involving ammonia supply system, ammonia injection system, catalyst, and other systems $[5,6]$. In contrast, SNCR denitrification technology has a low operating cost and can be applied in combination with various nitrogen oxide emission reduction technologies [7-10].

Han et al. [11] conducted SNCR denitrification tests on power station boilers. The results showed that the optimal reaction temperature for denitrification of ammonia and urea solutions is about $1000^{\circ} \mathrm{C}$, and the maximum denitrification efficiency of SNCR is about $90 \%$ under typical test conditions with an ammonia-nitrogen ratio of 1.5. Li and $\mathrm{Wu}$ [12] completed the simulation process of SNCR of the experimental device in CRF by numerical simulation. $\mathrm{Li}$ et al. [13] conducted a simulation study on the CFB boiler cyclone separator and analyzed the influence of temperature window and ammonia-nitrogen molar ratio (NSR) on denitrification efficiency. They found that the optimal temperature window is $850 \sim 1050^{\circ} \mathrm{C}$, and the optimal NSR is $1 \sim 1.5$. At present, SNCR technology research is mostly concentrated in the field of power station boilers. Due to the inhibitory effect of calcium compounds such as limestone on the reaction of SNCR in the decomposing furnace, there are relatively few research studies on SNCR in the field of cement decomposing furnace, which leads to the limitation of the development of this technology in the cement industry. However, because of its economy and convenience, SNCR technology has great potential in optimizing SNCR denitrification and improving SNCR denitrification efficiency of the decomposing furnace.

Based on previous studies, this paper, based on Fluent software platform, simulates the SNCR denitrification based on the new dry cement kiln decomposing furnace air 
fractional combustion. The effects of the injection location of urea solution along the height of the decomposing furnace, the ammonia-nitrogen molar ratio, and the injection velocity of urea solution on the $\mathrm{NO}$ concentration, $\mathrm{NH}_{3}$ escape amount, and denitrification efficiency are studied in this paper. The formulated SNCR denitrification process parameters with better denitrification efficiency are obtained.

\section{Numerical Simulation of SNCR in Decomposing Furnace}

2.1. The Geometric Model. The object of this simulation is a decomposing furnace with an output of $2500 \mathrm{t} / \mathrm{d}$ in a cement plant in Hunan. The model of the decomposing furnace is modeled according to the actual scale, as shown in Figures 1 and 2 . The pulverized coal and primary air in the decomposing furnace are sprayed into the furnace through the coal injection pipes on both sides of the lower column. The hightemperature flue gas from the end of the decomposing kiln enters the furnace through the bottom of the cone and is mixed with the pulverized coal airflow and the tertiary air for ignition and combustion [14]. The burnout air is sprayed into the furnace from the middle of the lower column, so that the pulverized coal and raw materials escaping from the core combustion zone continue to burn and decompose [15].

This article uses the ICEM software for simulating structural mesh, for improving the quality of the mesh, on the whole decomposing furnace using O-mesh technology, and the decomposing furnace reducing part and each entrance area mesh refinement processing, the calculation mesh is shown in Figure 3. The total number of grids was determined to be about 850,000 through mesh independence verification.

2.2. Calculation Model. The decomposing furnace model is complex and contains multiple high-speed airflow and mixed flow. The RNG $k-\varepsilon$ model can better deal with the strong turbulent flow with high strain velocity and large flow line bending degree $[16,17]$, which is adopted for the gasphase turbulence model in this study. The calculation formula is shown in the following equations:

$$
\begin{aligned}
& \frac{\partial(\rho k)}{\partial t}+\frac{\partial\left(\rho k \mu_{i}\right)}{\partial x_{i}}=\frac{\partial}{\partial x_{j}}\left[\alpha_{k}\left(\mu+\mu_{t}\right) \frac{\partial k}{\partial x_{j}}\right]+G_{k}+\rho \varepsilon \\
& \frac{\partial(\rho \varepsilon)}{\partial t}+\frac{\partial\left(\rho \varepsilon \mu_{i}\right)}{\partial x_{i}}=\frac{\partial}{\partial x_{j}}\left[\alpha_{\varepsilon}\left(\mu+\mu_{t}\right) \frac{\partial k}{\partial x_{j}}\right]+\frac{C_{1 \varepsilon}^{*}}{k} G_{k}-C_{2 \varepsilon} \rho \frac{\varepsilon^{2}}{k},
\end{aligned}
$$

where $\rho$ is the density of the gas, $\mathrm{kg} / \mathrm{m}^{3} ; k$ is turbulent kinetic energy, $J ; \varepsilon$ is the turbulent dissipation velocity; $\mu$ is the molecular viscosity coefficient; $\mu_{t}$ is the turbulent viscosity coefficient; and $C$ is the constant term coefficient.

Based on the detailed chemical reaction process of turbulent combustion in the decomposing furnace, component transport model and eddy dissipation conceptual

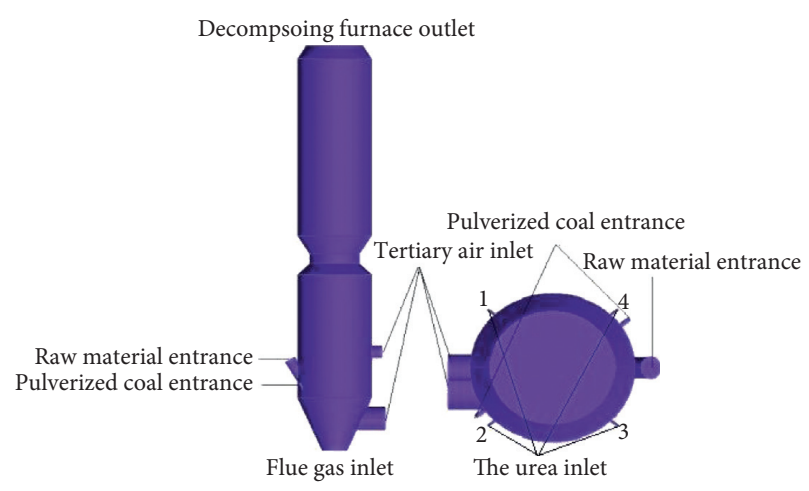

Figure 1: Geometry model of the decomposing furnace.

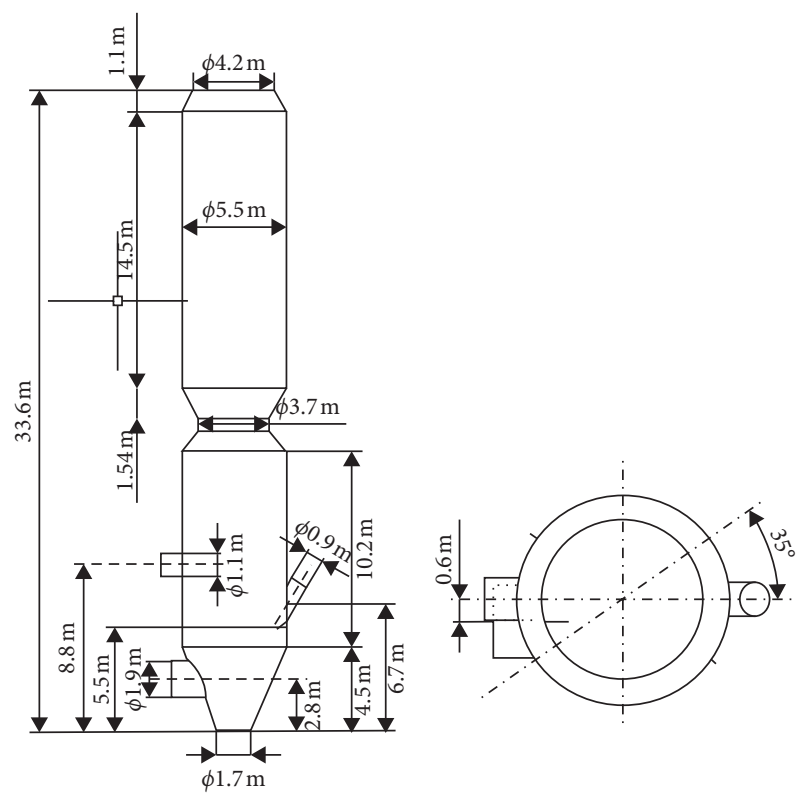

FIgURE 2: Dimensions of the decomposing furnace.

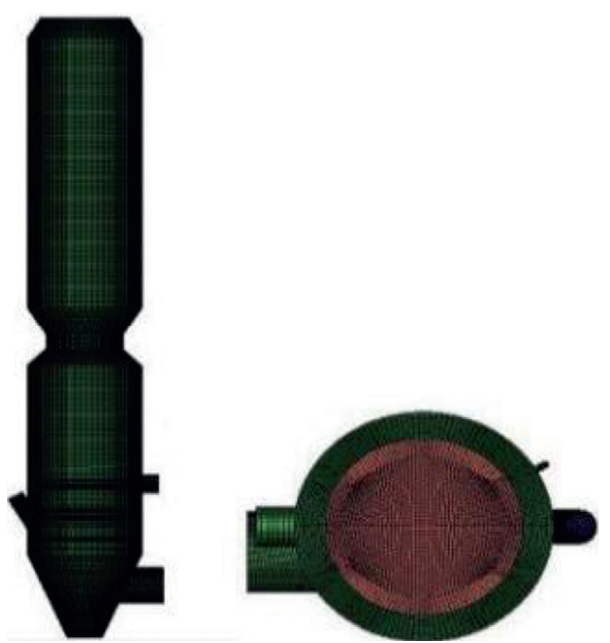

FIGURE 3: Decomposing furnace meshing diagram. 
model (EDC) are selected in this paper, in which the diffusion/dynamic model is used for coke combustion and limestone decomposing. The moisture only considers evaporative heat absorption. The $\mathrm{NO}_{\mathrm{x}}$ reaction model included in Fluent is selected for the pollutant model. Since under the condition of fractional air and furnace temperature (less than $1000^{\circ} \mathrm{C}$ ) of the decomposing furnace, the rapid $\mathrm{NO}_{\mathrm{x}}$ and thermal $\mathrm{NO}_{\mathrm{x}}$ generated by the combustion of pulverized coal particles are few and negligible, only fuel $\mathrm{NO}_{\mathrm{x}}$ is considered in the simulation, and the SCNR model is activated to use urea as the reducing agent of the reaction. According to the characteristics of pulverized coal particles and urea particles in the furnace, the discrete phase model (DPM) is used to calculate the particle phase flow, and the diameter of urea droplets is set at $50-200 \mu \mathrm{m}$. Since the proportion of particles in the mixed phase is less than $10 \%$, the particles (assumed to be spherical) are regarded as the dilute phase, and the interactions between particles could be ignored, and only the resistance and gravity are taken into account $[18,19]$. The temperature in the furnace is relatively high, and the temperature in the core combustion zone is about $1250 \mathrm{~K}$. The main heat transfer mode is radiation heat transfer, so the radiation model adopts p1 model [20]. The chemical reaction mechanism of all $\mathrm{NO}_{\mathrm{x}}$ involved in the decomposing furnace with limestone is shown in Table 1.

2.3. The Boundary Conditions. The boundary conditions of decomposing furnaces are summarized as shown in Tables 2 and 3 through the operating parameters, coal burning analysis data, and reasonable assumptions of running kilns.

2.4. SNCR Denitrification Design. In the process of SNCR denitrification, the main factors influencing the denitrification effect are reaction temperature, residence time of reducing agent, mixing degree of reducing agent, and flue gas and ammonia-nitrogen molar ratio. Combined with the actual situation of the cement manufacturing process, this paper mainly studied the effect of the injection location of urea solution, NSR, and injection speed of urea solution on denitrification. At the same time, in order to achieve the uniform mixing of the urea solution and the $\mathrm{NO}_{\mathrm{x}}$ in the flue gas, this article will arrange four symmetrical nozzles along the different decomposing furnace height positions, and the specific layout position is shown as 1,2,3, and 4 in Figure 1.

The SNCR denitrification was studied using numerical simulation combined with experimental study, and the details are as follows:

(1) Firstly, a combustion model of the $2500 \mathrm{t} / \mathrm{d}$ decomposing furnace was established. According to the established combustion model, the numerical simulation of the decomposing furnace was carried out by Fluent software. In order to validate the reliability of the combustion model, a series of experiments was performed on the $2500 \mathrm{t} / \mathrm{d}$ decomposing furnace. The temperature of the furnace outlet was measured by the gas pump thermocouple, and the flue gas composition was measured by the KM940 flue gas analyzer. The simulation results were compared with the experimental results to obtain a more reliable decomposing furnace combustion model.

(2) Secondly, the SNCR denitrification reaction is added to the obtained combustion model. The effects of the injection location of the urea solution, NSR, and the injection speed of the urea solution on SNCR denitrification were studied by numerical simulation. The urea solution is injected into the furnace at the heights of $6,8,10,12,14,16$, and $18 \mathrm{~m}$, respectively. The NSR gradually increases from 1.0 to 2.0 , whose increment is 0.2 . The injection velocities of the urea solution are $20,40,60$, and $80 \mathrm{~m} / \mathrm{s}$, respectively. The desulfurization efficiency and nitrogen oxide emissions under various parameters can be obtained by numerical simulation, and the process parameters with the best desulfurization effect can be concluded.

(3) Finally, based on the simulation results, the operation parameters of the $2500 \mathrm{t} / \mathrm{d}$ decomposition furnace were adjusted, and the temperature and flue gas composition of the decomposition furnace outlet were measured again. Then the measured results are compared with the simulation results to provide a reliable basis for the simulated parameters.

\section{Combustion Simulation and Experimental Verification}

3.1. Simulation Analysis of Temperature Field and Concentration Field. The simulation results of combustion temperature and concentration of each component in the decomposing furnace are shown in Figure 4 . The combustion temperature in the decomposing furnace is shown in Figure 4(a). The junction of the bottom cone and the lower column of the decomposing furnace is the core combustion zone. The highest combustion temperature is $1400 \mathrm{~K}$ and the average temperature is about $1250 \mathrm{~K}$. The temperature distribution in the decomposing furnace is relatively uniform, which basically meets the requirements of the raw material decomposing process. After passing through the core combustion zone, the temperature gradually decreases along the $Z$-axis direction, and the temperature rises slightly when passing through the upper column, until the outlet temperature of the decomposing furnace drops to $1200 \mathrm{~K}$. The distribution of $\mathrm{O}_{2}, \mathrm{CO}_{2}$, and $\mathrm{CO}$ is shown in Figures 4(b)-4(d). In the core combustion area, pulverized coal burns violently, and due to the large consumption of oxygen, the $\mathrm{O}_{2}$ concentration drops sharply. Meanwhile, the $\mathrm{CO}_{2}$ concentration increases rapidly and is accompanied by the generation of $\mathrm{CO}$. The $\mathrm{O}_{2}$ concentration at the outlet of the decomposing furnace drops to $1.26 \%$, the $\mathrm{CO}_{2}$ concentration increases to $31 \%$, and the $\mathrm{CO}$ concentration value is $0.88 \%$. The distribution cloud diagram of $\mathrm{NO}$ is shown in Figure $4(\mathrm{e})$. The concentration of $\mathrm{NO}$ in the cone of the decomposing furnace is relatively small, and in a local area, $\mathrm{NO}$ is generated in large amount with the pyrolysis of volatiles, and its peak value is $1648 \mathrm{mg} / \mathrm{m}^{3}$. As the height of 
TABLE 1: The equations of the conversion of $\mathrm{NO}_{\mathrm{x}}$ and limestone.

\begin{tabular}{|c|c|c|c|c|}
\hline No. & Reactions $k_{f}=A T^{b} \exp (-E / R T)$ & $A\left(\mathrm{~s}^{-1}\right)$ & $\mathrm{b}$ & $E(\mathrm{~kJ} / \mathrm{mol})$ \\
\hline (R1) & $\mathrm{NH}_{3}+1.25 \mathrm{O}_{2} \longrightarrow \mathrm{NO}+1.5 \mathrm{H}_{2} \mathrm{O}$ & $3.10 E+08$ & 0 & $8.31 E+07$ \\
\hline (R2) & $\mathrm{NH}_{3}+0.75 \mathrm{O}_{2} \longrightarrow 0.5 \mathrm{~N}_{2}+1.5 \mathrm{H}_{2} \mathrm{O}$ & $4.96 E+08$ & 0 & $8.31 E+07$ \\
\hline (R3) & $\mathrm{HCN}+0.75 \mathrm{O}_{2} \longrightarrow \mathrm{CNO}+0.5 \mathrm{H}_{2} \mathrm{O}$ & $2.14 E+04$ & 0 & $8.31 E+07$ \\
\hline (R4) & $\mathrm{CNO}+0.5 \mathrm{O}_{2} \longrightarrow \mathrm{NO}+\mathrm{CO}$ & $1.02 E+12$ & 0 & $2.12 E+08$ \\
\hline (R5) & $\mathrm{CNO}+\mathrm{NO} \longrightarrow \mathrm{N}_{2} \mathrm{O}+\mathrm{CO}$ & $1.02 E+12$ & 0 & $2.12 E+08$ \\
\hline (R6) & $\mathrm{NO}+\mathrm{NH}_{3}+0.25 \mathrm{O}_{2} \longrightarrow \mathrm{N}_{2}+1.5 \mathrm{H}_{2} \mathrm{O}$ & $1.10 E+12$ & 0 & $2.77 E+04$ \\
\hline (R7) & $\mathrm{NO}+\mathrm{CO} \longrightarrow 0.5 \mathrm{~N}_{2}+\mathrm{CO}_{2}$ & $1.95 E+07$ & 0 & $1.58 E+08$ \\
\hline (R8) & $\mathrm{N}_{2} \mathrm{O}+0.5 \mathrm{O}_{2} \longrightarrow \mathrm{N}_{2}+\mathrm{O}_{2}$ & $1.50 E+11$ & 0 & $1.68 E+08$ \\
\hline (R9) & $\mathrm{N}_{2} \mathrm{O}+\mathrm{CO} \longrightarrow \mathrm{N}_{2}+\mathrm{CO}_{2}$ & $1.24 E+09$ & 0 & $4.92 E+07$ \\
\hline$(\mathrm{R} 10)$ & $\mathrm{CO}\left(\mathrm{NH}_{2}\right)_{2} \longrightarrow \mathrm{NH}_{3}+\mathrm{HNCO}$ & $1.27 E+04$ & 0 & $1.55 E+04$ \\
\hline (R11) & $\mathrm{CO}\left(\mathrm{NH}_{2}\right)_{2}+\mathrm{H}_{2} \mathrm{O} \longrightarrow 2 \mathrm{NH}_{3}+\mathrm{CO}_{2}$ & $6.13 E+10$ & 0 & $2.10 E+04$ \\
\hline$(\mathrm{R} 12)$ & $\mathrm{CaCO}_{3} \longrightarrow \mathrm{CaO}+\mathrm{CO}_{2}$ & $6.08 E+04$ & 0 & $2.05 E+08$ \\
\hline
\end{tabular}

TABLE 2: Boundary conditions.

\begin{tabular}{lcccc}
\hline The boundary conditions & Temperature $(\mathrm{K})$ & Mass flow $(\mathrm{kg} / \mathrm{s})$ & Velocity $(\mathrm{m} / \mathrm{s})$ & - \\
\hline Tertiary air (reducing air/burnout air) & 1300 & $18.57(15.83 / 2.74)$ & 30 & - \\
Decomposing furnace flue gas & 1400 & - & - & - \\
Pulverized coal & 321 & 2.68 & - & - \\
Primary air & 321 & - & - & - \\
$\mathrm{CaCO}_{3}$ & 1200 & - & - & -1200 \\
Decomposing furnace outlet & - & Pa) & - \\
\hline
\end{tabular}

TABLE 3: Ultimate analysis of coal.

\begin{tabular}{llccccccc}
\hline \multicolumn{1}{c}{ Ultimate analysis (wt. \%) } & \multicolumn{3}{c}{ Lower heating value $Q_{\text {net }}(\mathrm{kJ} / \mathrm{kg})$} \\
\hline$C_{\mathrm{ar}}$ & $H_{\mathrm{ar}}$ & $\mathrm{O}_{\mathrm{ar}}$ & $N_{\mathrm{ar}}$ & $S_{\mathrm{ar}}$ & $A_{\mathrm{ar}}$ & $M_{\mathrm{ar}}$ & $V_{\mathrm{daf}}$ & 32789.3 \\
\hline
\end{tabular}

the furnace increases, the tertiary air enters the furnace in stages, and a reducing atmosphere is generated due to fuelrich combustion above the core combustion zone. Part of the NO is reduced along the height of the decomposing furnace, which gradually reduces the NO concentration. The unburned residual pulverized coal in the core area will be burned with the over-fire air as the smoke rises, and the secondary combustion will occur, which will increase the $\mathrm{CO}_{2}$ concentration in the flue gas and gradually increase the NO concentration. The final NO concentration at the outlet of the decomposing furnace is $743 \mathrm{mg} / \mathrm{m}^{3}$.

3.2. Experimental Verification. In this paper, based on the feasibility of measurement, the flue gas temperature and component concentration at the outlet of the Chenzhou $2500 \mathrm{t} / \mathrm{d}$ decomposing furnace are measured and compared with the simulation results. Four measuring points are set at the outlet of the decomposing furnace, and the positions are $0,0.5,1.0$, and $1.5 \mathrm{~m}$ away from the center of the measuring point. Exhaust thermocouple (s-type thermocouple, Siemens (China) Co., LTD.) was used to measure the temperature of flue gas. The KM940 flue gas analyzer made in Britain with high test accuracy and high temperature adaptability is used to measure the concentration of flue gas components. In order to reduce the influence of zero drift of the instrument itself on the accuracy of the test, the instrument used before the test shall be strictly calibrated according to the regulations. Test values and simulation values of decomposing furnace outlet parameters are summarized in Table 4 . It can be found from Table 4 that the error between the simulation results and the actual measured values is small, so the experimental results can be replaced by simulation. The simulation data used to support the findings of this study are included within the article, and the experimental data used to support the findings of this study are available from the corresponding author upon request.

\section{Analysis of SNCR Simulation Results}

4.1. Analysis of Results of Urea Solution Injection Position. The injection position of the urea solution determines the residence time of the urea in the furnace and the temperature conditions under which the urea reacts. When injected into the low position, the residence time is long, but the reaction temperature is too high, and the urea is easily oxidized; when injected into the high position, the reaction temperature is too low and the residence time is short, which easily leads to an increase in the amount of $\mathrm{NH}_{3}$ escape. This article selects 

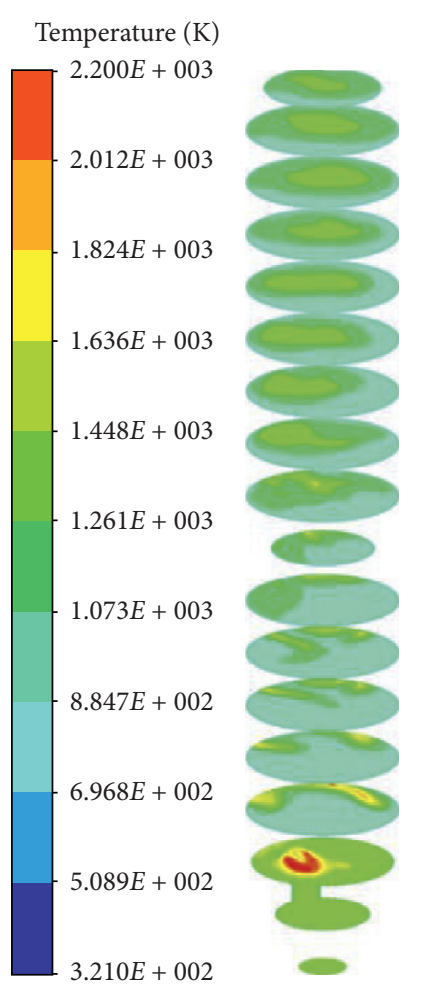

(a)

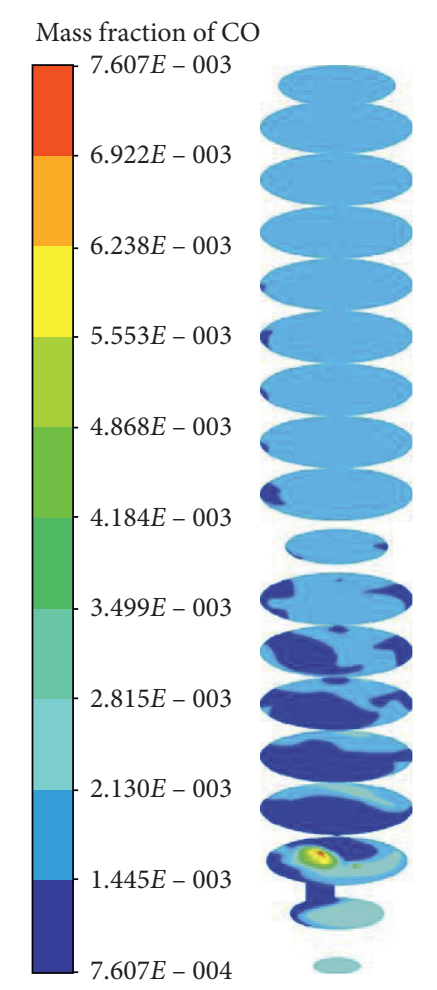

(d)

(b)
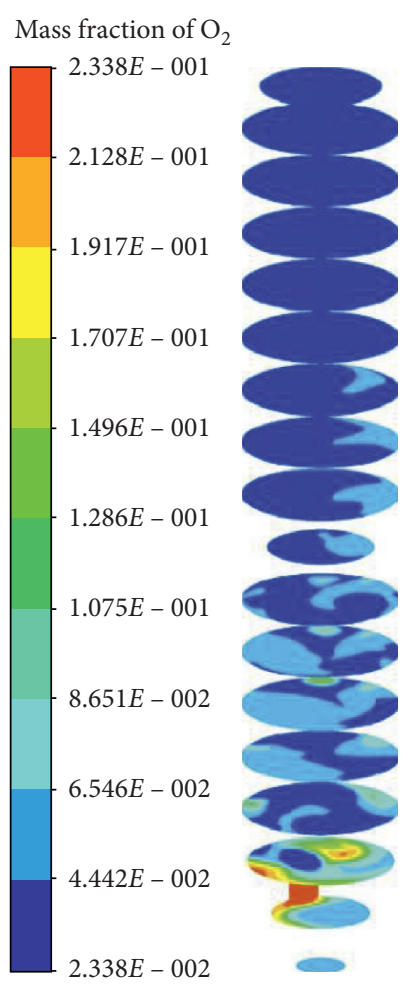

(e)
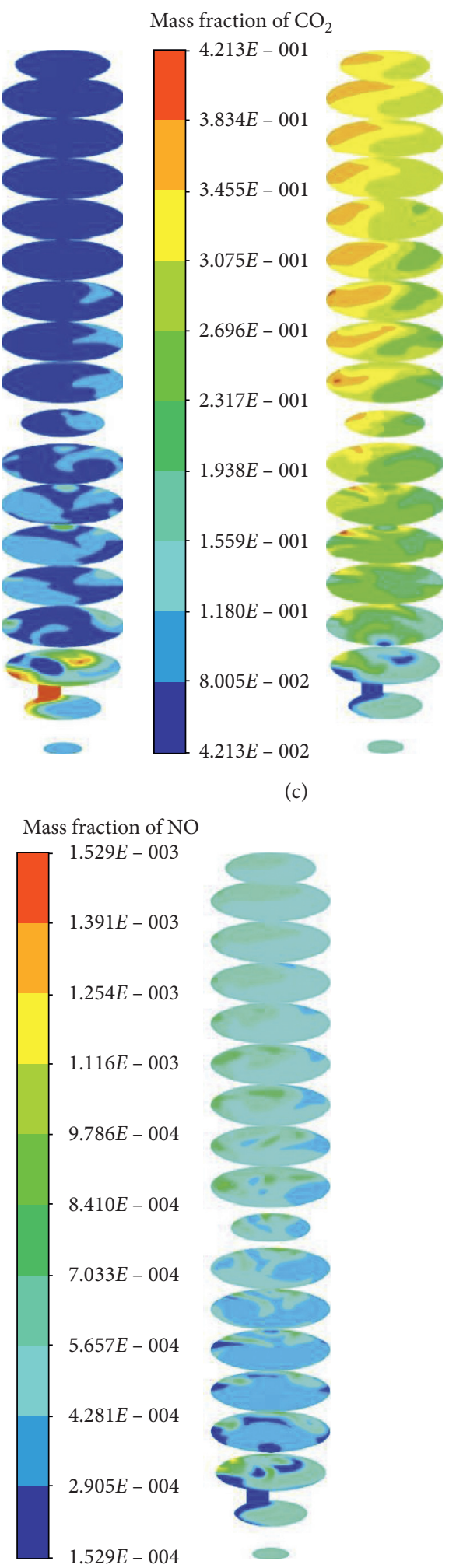

(c)

Figure 4: Numerical simulation of combustion in the decomposing furnace. (a) Temperature. (b) $\mathrm{O}_{2}$. (c) $\mathrm{CO}_{2}$. (d) CO. (e) NO.

the urea solution spray into the position, respectively, along the height direction (the $Z$-axis) of the decomposing furnace is $6,8,10,12,14,16$, and $18 \mathrm{~m}$, and its temperature ranges from 950 to $1250 \mathrm{~K}$.
The distribution of $\mathrm{NO}$ and $\mathrm{NH}_{3}$ mass flow at different heights of the decomposing furnace under different injection positions of urea solution is shown in Figure 5. Under different incident positions of urea solution, the 
TABLE 4: Comparison of the measured data and simulated data.

\begin{tabular}{|c|c|c|c|c|c|c|c|c|}
\hline \multirow[t]{2}{*}{ Data categories } & \multicolumn{4}{|c|}{$\begin{array}{c}\text { Decomposing furnace outlet flue gas } \\
\text { temperature }(\mathrm{K})\end{array}$} & \multicolumn{3}{|c|}{ Mass fraction (\%) } & \multirow{2}{*}{$\begin{array}{c}\text { Concentration }\left(\mathrm{mg} / \mathrm{m}^{3}\right) \\
\mathrm{NO}\end{array}$} \\
\hline & $\mathrm{a}$ & $\mathrm{b}$ & c & $\mathrm{d}$ & $\mathrm{O}_{2}$ & $\mathrm{CO}_{2}$ & $\mathrm{CO}$ & \\
\hline Experimental data & 1302.8 & 1310.4 & 1303.4 & 1283.2 & 3.10 & 73.1 & 0.18 & 787.30 \\
\hline Simulation data & 1327.1 & 1337.7 & 1266.0 & 1240.0 & 2.90 & 69.3 & 0.19 & 743 \\
\hline Relative error & 1.87 & 2.08 & 2.94 & 3.34 & 6.75 & 5.10 & 5.56 & 5.97 \\
\hline
\end{tabular}
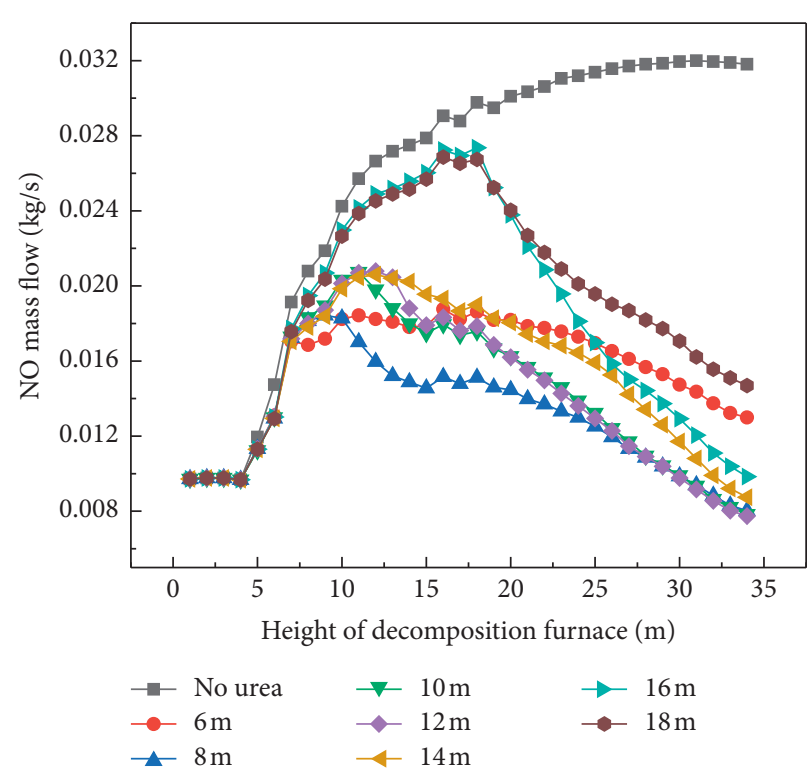

(a)

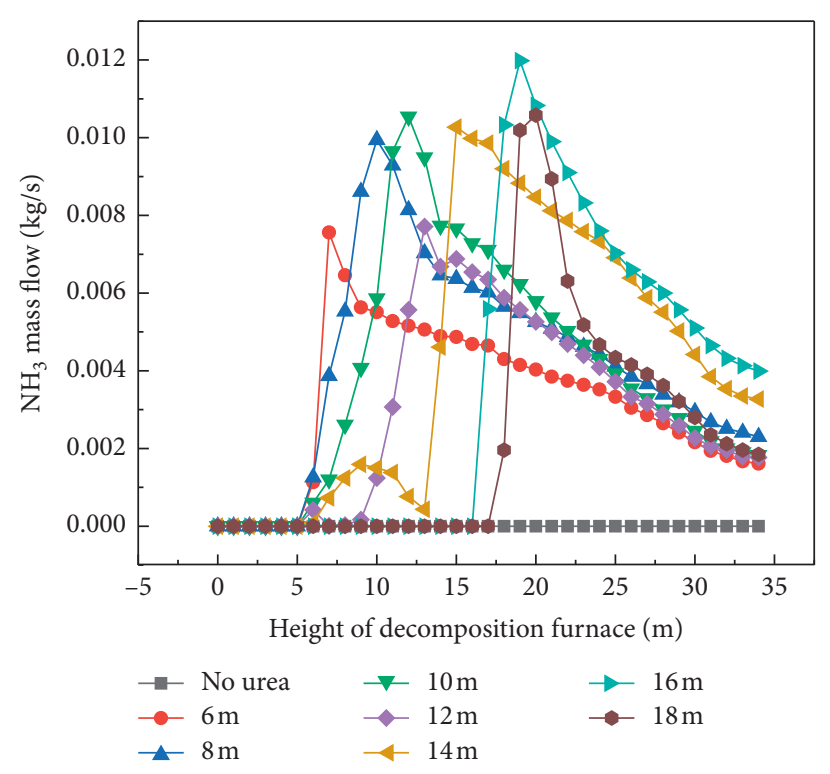

(b)

FIgURE 5: Flow curves of $\mathrm{NO}$ and $\mathrm{NH}_{3}$ in the decomposing furnace under different injection positions. (a) $\mathrm{NO}$ and (b) $\mathrm{NH}_{3}$.

concentration of $\mathrm{NO}$ and $\mathrm{NH}_{3}$ in the decomposing furnace generally increases first and then decreases. The combustion of pulverized coal particles in the core combustion zone and the reducing tertiary air produces a large amount of NO, which causes a sharp increase in the NO concentration at the junction of the decomposing furnace cone and the lower half of the cylinder. Fuel-rich combustion in the core combustion zone consumes a large amount of oxygen due to the tertiary air classification. A reducing atmosphere is generated above the core combustion zone to reduce part of the $\mathrm{NO}$, and the increase in $\mathrm{NO}$ concentration becomes slower. When the urea solution is injected into the decomposing furnace from a low height, the residence time of the urea solution is long and the reaction temperature is too high, which causes the urea to be easily oxidized. When the urea solution is injected into the decomposing furnace from a high height, the residence time of the urea solution is short and the reaction temperature is too low, which results in an increase in the concentration of $\mathrm{NH}_{3}$ escape. The distribution curve of $\mathrm{NO}$ and $\mathrm{NH}_{3}$ concentrations in the cross section of different injection heights of decomposing furnaces is shown in Figures 5(a) and 5(b). From Figures 5(a) and $5(\mathrm{~b})$, when the injection height is $6 \mathrm{~m}$, the peak concentrations of $\mathrm{NO}$ and $\mathrm{NH}_{3}$ are lower. The reason is that the urea solution enters the furnace at a lower position, which is close to the core combustion zone. And its average temperature is about $1300 \mathrm{~K}$, which causes some of the $\mathrm{NH}_{3}$ and HNCO produced by the decomposing of urea to be oxidized to NO. Combined with the reducing ability of the urea decomposing product itself and the reason for being oxidized at high temperature, the two restrict each other and cause the lower peak concentration of $\mathrm{NO}$ and $\mathrm{NH}_{3}$ in the furnace. When the injection heights are 16 and $18 \mathrm{~m}$, the NO concentration is increasing under the height of the decomposing furnace below $15 \mathrm{~m}$, and its peak value is $1491 \mathrm{mg} / \mathrm{m}^{3}$. And when the injection height is $16 \mathrm{~m}$, the $\mathrm{NH}_{3}$ escape amount is the largest, which is caused by the urea solution injection position being too high and the residence time shortened.

From the above analysis, it can be seen that the injection position of the urea solution has a significant influence on the ability to reduce nitrogen oxides. The variations of NO concentration and $\mathrm{NH}_{3}$ escape concentration with injection height of urea solution are shown in Figure 6, and the variation of denitrification efficiency with injection height of urea solution is shown in Figure 7. The NO concentration and $\mathrm{NH}_{3}$ escape concentration curves are " $U$ " and " $M$," respectively. When the injection height of the urea solution increases, the NO concentration at the outlet of the decomposing furnace decreases first and then increases. 


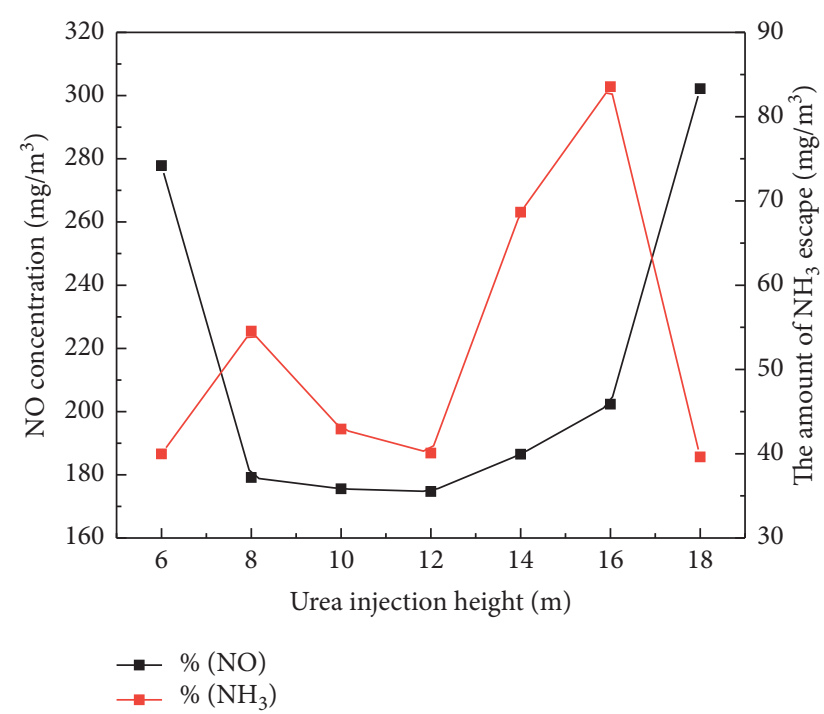

Figure 6: $\mathrm{NO}$ concentration and $\mathrm{NH}_{3}$ of outlet under different injection positions.

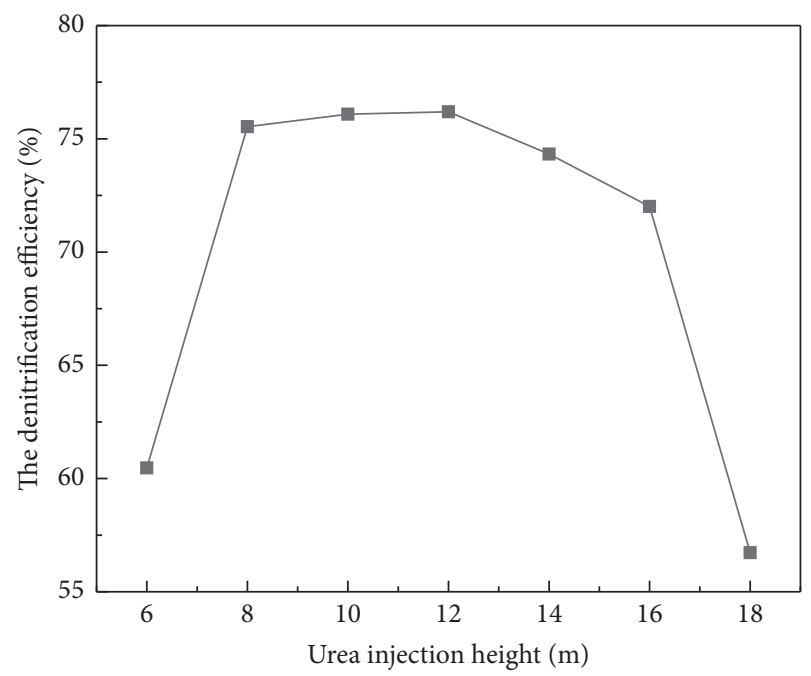

Figure 7: Denitrification efficiency under different injection positions.

Especially when the injection position is more than $16 \mathrm{~m}$, the NO concentration rapidly increases from $207 \mathrm{mg} / \mathrm{m}^{3}$ to $320 \mathrm{mg} / \mathrm{m}^{3}$, and the amount of $\mathrm{NH}_{3}$ escaping decreased significantly from $83.46 \mathrm{mg} / \mathrm{m}^{3}$ to $39.65 \mathrm{mg} / \mathrm{m}^{3}$. The reason is that the wind is divided into three winds (burnout wind) into the furnace and mixes with the flue gas, and the combustion of residual coal powder increases the temperature of the upper half of the column in the decomposing furnace, so that part of $\mathrm{NH}_{3}$ is oxidized to $\mathrm{NO}$. When the injection height is $12 \mathrm{~m}$, the NO concentration and the escape amount of $\mathrm{NH}_{3}$ are at a low level. It can be seen from Figure 7 that the SNCR denitrification efficiency curves at different heights are "inverted U," and the denitrification nitration efficiency increases first and then decreases as the injection position increases. A comprehensive analysis of the simulation results of SNCR at different injection heights of urea solution shows that the optimized injection height is $12 \mathrm{~m}$. At this time, the NO concentration is $176 \mathrm{mg} / \mathrm{m}^{3}$, the amount of $\mathrm{NH}_{3}$ escape is $39.98 \mathrm{mg} / \mathrm{m}^{3}$, and the denitrification efficiency is $76.26 \%$.

4.2. Analysis of Ammonia-Nitrogen Molar Ratio (NSR) Results. According to the above SNCR chemical reaction principle, it is known that theoretically reducing $1 \mathrm{~mol}$ of NO requires $1 \mathrm{~mol}$ of $\mathrm{NH}_{3}$, which is NSR is equal to 1 . However, in practical engineering applications, it cannot guarantee that all decomposed $\mathrm{NH}_{3}$ completely reacts with $\mathrm{NO}$ in the flue gas due to the complicated chemical reaction of urea and the complicated mixing process of the gas flow in the decomposing furnace. When NSR is greater than 2 , excessive consumption of reducing agent will increase the running cost and increase the amount of $\mathrm{NH}_{3}$ escape. The research scheme of the effect of different ammonia-nitrogen ratios (NSR) on denitrification is as follows: keep other parameter settings unchanged (from the above analysis results, the injection height of the urea solution is maintained at $12 \mathrm{~m}$, and the NSR gradually increased from 1.0 to 2.0 (successive increments are 0.2 )), and carry out simulation research on five sets of NSR schemes.

The variations of concentrations of $\mathrm{NO}$ and $\mathrm{NH}_{3}$ in the decomposing furnace with NSR are shown in Figure 8. From the analysis in Figure 8, with different NSR, changes in the $\mathrm{NO}_{\mathrm{x}}$ and $\mathrm{NH}_{3}$ concentration in the decomposing furnace are more obvious. When the decomposing furnace height is below $11 \mathrm{~m}$, the changes of $\mathrm{NO}$ and $\mathrm{NH}_{3}$ concentrations in the furnace are basically synchronized. Between $11 \mathrm{~m}$ and $13 \mathrm{~m}$, as the NSR increases, the peak value of NO concentration in the furnace decreases, and the peak value of $\mathrm{NH}_{3}$ concentration increases. When the height of the decomposing furnace is more than $15 \mathrm{~m}$, the NO concentration in the decomposing furnace generally decreases, and the slope of the NO curve increases with the increase of NSR. The reason is that when NSR is 1 , the reduction reaction velocity increases with the increase of NSR, so more NO will be reduced. However, when NSR reached 1.8, NO in the decomposer had reached a low concentration and could not be reduced easily. If $\mathrm{NH}_{3}$ continues to be increased, it will not only improve the denitrification efficiency, but also increase the $\mathrm{NH}_{3}$ escapement.

The variations of $\mathrm{NO}$ concentration and $\mathrm{NH}_{3}$ escape amount at the outlet of the decomposing furnace with NSR are shown in Figure 9. It can be seen from Figure 9 that the change trend of the $\mathrm{NO}$ concentration and the $\mathrm{NH}_{3}$ escape amount line is just the opposite. With the increase of NSR, the $\mathrm{NO}$ concentration gradually decreases and the $\mathrm{NH}_{3}$ escape amount gradually increases. When the NSR is 1.0 , the NO concentration and $\mathrm{NH}_{3}$ escape concentration are $373.94 \mathrm{mg} / \mathrm{m}^{3}$ and $16.42 \mathrm{mg} / \mathrm{m}^{3}$, respectively. At this time, the NO concentration of the decomposing furnace is the highest. When the NSR is greater than 1.8 , the $\mathrm{NH}_{3}$ escape concentration rises linearly, and the NO concentration decreases slowly at this time, indicating that the urea's ability to reduce NO tends to be saturated. The denitrification 


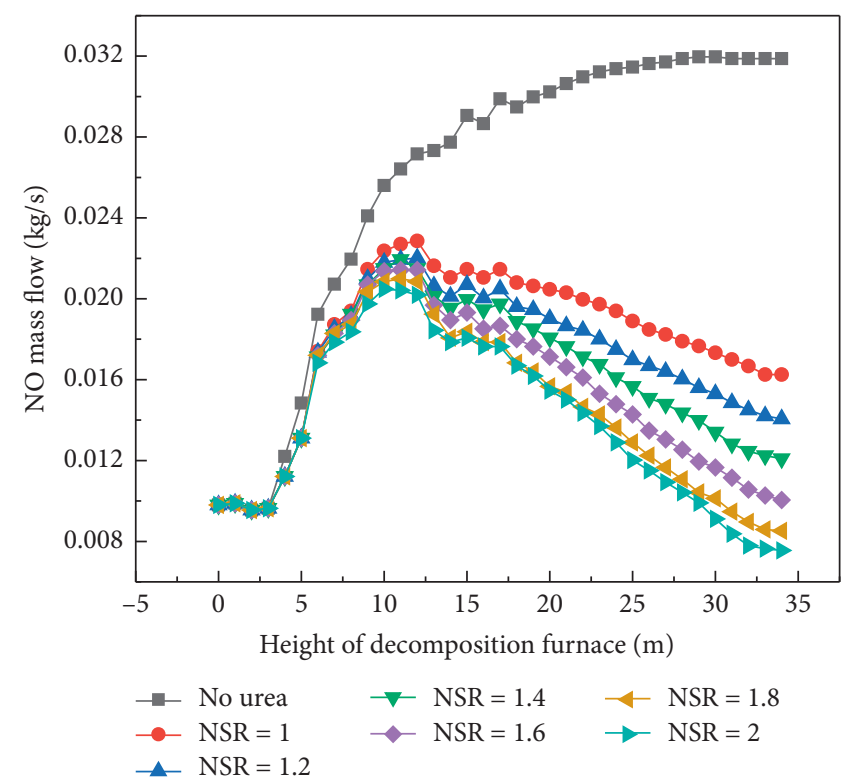

(a)

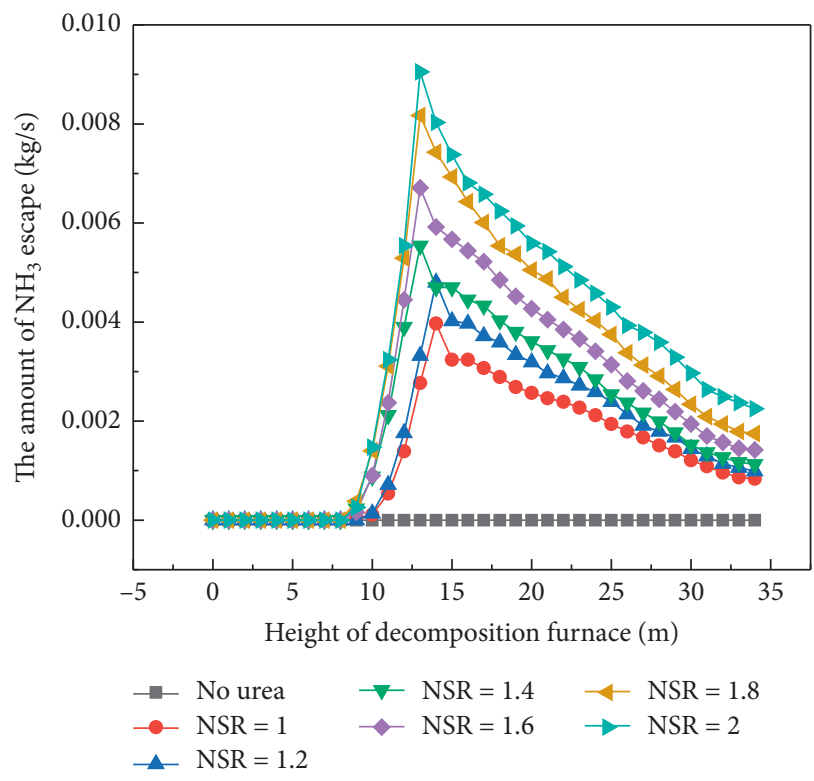

(b)

FIgURE 8: Flow curves of $\mathrm{NO}$ (a) and $\mathrm{NH}_{3}$ (b) in the decomposing furnace with different NSR.

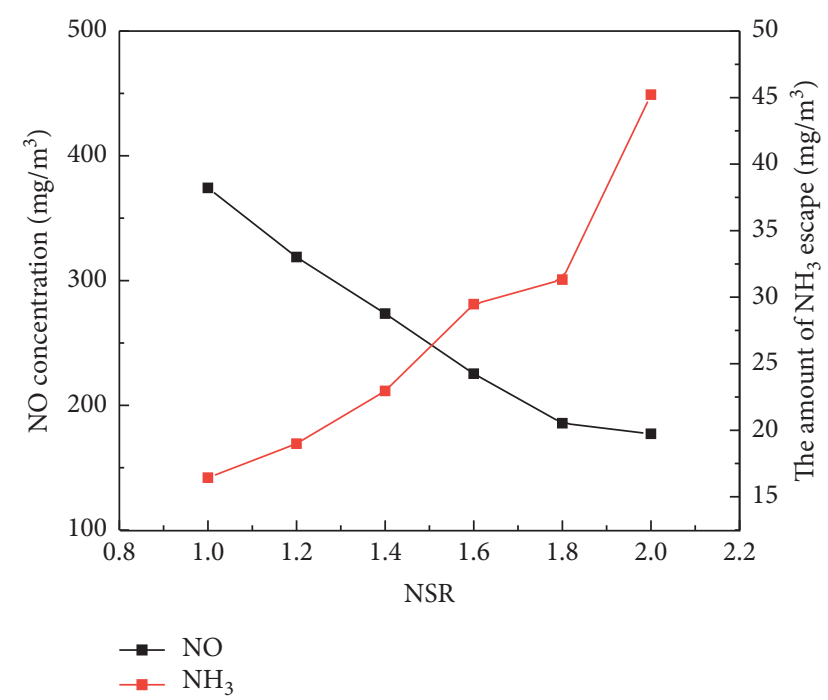

Figure 9: Variation of $\mathrm{NO}$ concentration and $\mathrm{NH}_{3}$ escape concentration at the outlet of the decomposing furnace with NSR.

efficiency curves at different NSR are shown in Figure 10. It can be seen from Figure 10 that the denitrification efficiency increases with increasing NSR. Comprehensive analysis of SNCR simulation results under different NSR shows that when the NSR is increased from 1.0 to 1.8 , the denitrification efficiency is relatively evenly improved. This is because the NO concentration in the furnace is higher at this time, and the SNCR reaction is stronger. Increasing NSR will allow more NO to be reduced. But when the NSR is greater than 1.8 , the denitrification efficiency rise velocity begins to decrease, and the amount of $\mathrm{NH}_{3}$ escape will increase much, so the optimal NSR is 1.8. Under this condition, the NO concentration of the decomposing furnace is $187.60 \mathrm{mg} / \mathrm{m}^{3}$,

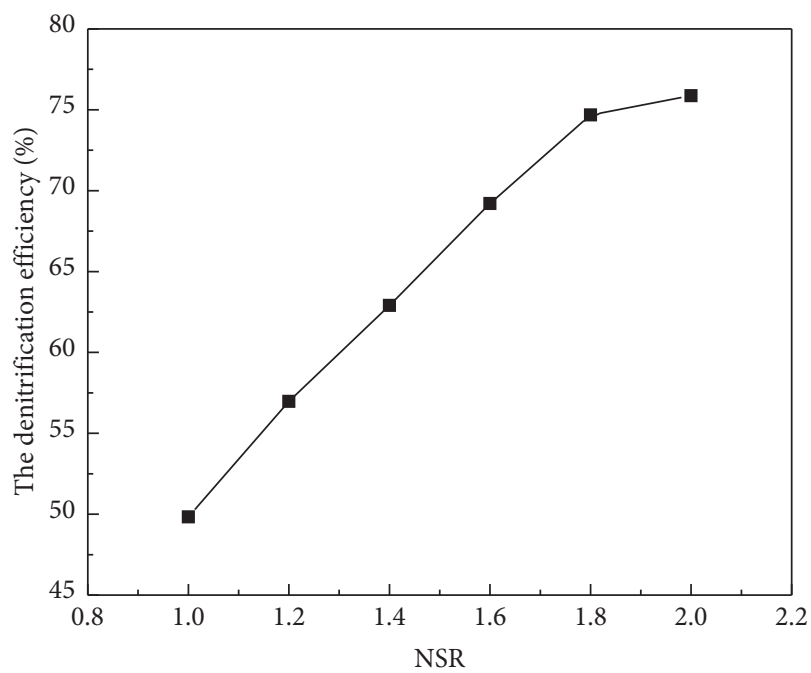

FIGURE 10: Variation of denitrification efficiency with NSR.

the $\mathrm{NH}_{3}$ escape concentration is $32.40 \mathrm{mg} / \mathrm{m}^{3}$, and the denitrification efficiency is $74.75 \%$.

4.3. Analysis of Urea Spray Velocity Results. The influence of the spraying velocity of the urea solution on the denitrification effect is mainly manifested in two aspects: the mixing degree of the urea solution with the mainstream smoke and the evaporation speed of the urea solution. Based on the above research, when the injection height of the reducing agent is $12 \mathrm{~m}$ and the molar ratio of ammonia and nitrogen is 1.8 , simulations of different reducing agent injection velocity are performed. The jet velocity is from $20,40,60$, and $80 \mathrm{~m} / \mathrm{s}$ in order from low to high. 


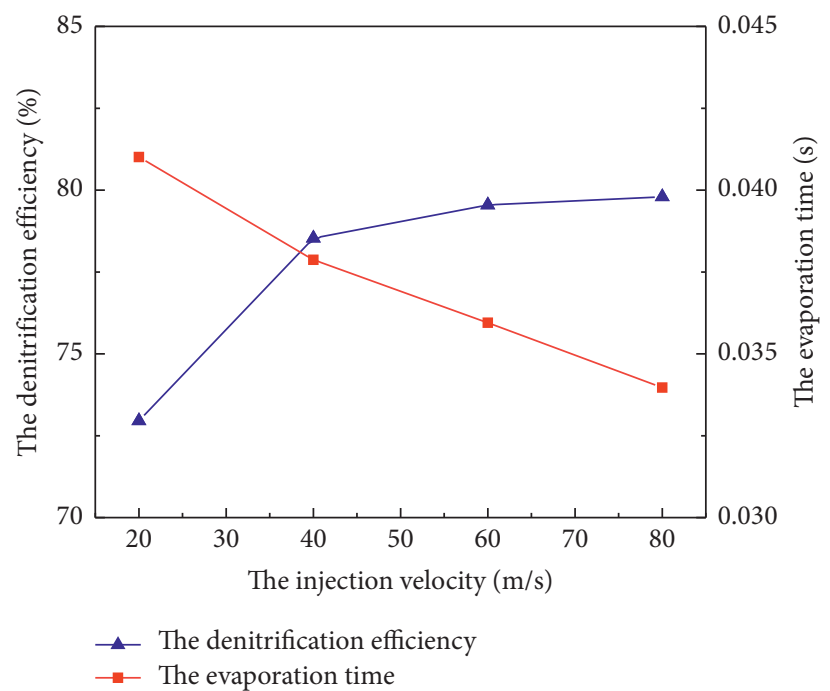

FIgURE 11: Evaporation time of urea solution and denitrification efficiency at different injection velocities.

The variations of evaporation time and denitrification efficiency of urea solution in the decomposing furnace with the spray velocity are shown in Figure 11. The variation of NO concentration and $\mathrm{NH}_{3}$ escape concentration at the outlet of the decomposing furnace with the spray velocity of urea solution is shown in Figure 12. It can be seen from Figure 11 that the denitrification efficiency gradually increases with the increase in spraying velocity. Increasing the spray velocity and increasing the mixing speed of the urea solution and the flue gas in the decomposing furnace strengthen the heat transfer between the main flue gas stream and the urea solution, which accelerates the evaporation process of the urea solution and makes the urea decompose in advance in a suitable temperature window. At the same time, the increase of the spray velocity is conducive to extending the range of the urea solution in the depth direction of the decomposing furnace, thereby enhancing the degree of mixing of urea and the main flue gas stream and improving the denitrification efficiency. It can be seen from Figure 12 that the urea solution spray velocity increases, and the $\mathrm{NH}_{3}$ concentration at the outlet of the decomposing furnace decreases first and then increases. This indicates that there is an optimal value for the injection velocity, and beyond this optimal value, the denitrification effect is not significantly improved, and at the same time, the $\mathrm{NH}_{3}$ escape concentration at the outlet of the decomposing furnace is increased.

Based on the analysis in Figures 11 and 12, it can be seen that it is reasonable to choose a urea solution spray velocity of $40 \mathrm{~m} / \mathrm{s}$. At this time, the urea solution evaporation time is $0.038 \mathrm{~s}$, and the $\mathrm{NO}$ concentration and $\mathrm{NH}_{3}$ escape concentration at the outlet of the decomposing furnace are $350 \mathrm{mg} / \mathrm{m}^{3}$ and $9.02 \mathrm{mg} / \mathrm{m}^{3}$, and the denitrification efficiency is $63.54 \%$.

\section{SNCR Simulation Test Verification}

The simulation results were verified by the test results of a decomposing furnace of a cement plant in Hunan Province. The $\mathrm{NH}_{3}$ escape concentration and $\mathrm{NO}$ concentration at the

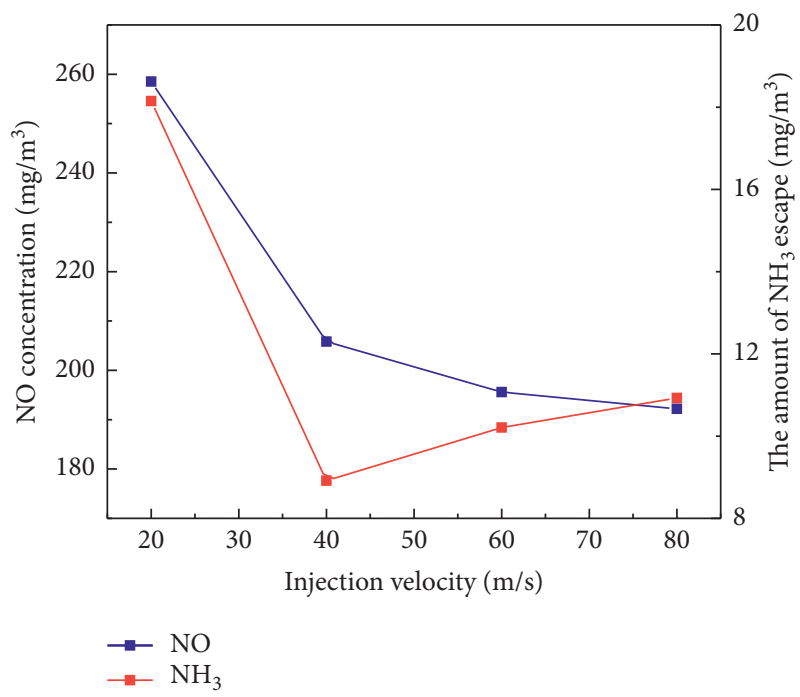

Figure 12: The variations of $\mathrm{NO}$ and $\mathrm{NH}_{3}$ concentrations at the outlet of the decomposing furnace with spray velocity.

outlet of the decomposing furnace were measured for verification. The layout of the measurement points of the test is exactly the same with that of the simulation. Combined with verifying the actual operation of SNCR denitrification in the decomposing furnace, the SNCR denitrification parameter settings of the decomposing furnace are summarized in Table 5, and the comparison between the SNCR simulation results and the test results is summarized in Table 6. The simulation data used to support the findings of this study are included within the article, and the experimental data used to support the findings of this study are available from the corresponding author upon request.

After verification, the relative error between the test results and the simulation results is within $10 \%$, which is within the allowable range. Therefore, the SNCR simulation calculation model has good reliability, and the simulation result can be used for production guidance. 
TABle 5: Parameter settings of SNCR.

\begin{tabular}{|c|c|c|c|c|c|c|}
\hline & The injection & ion $(x, y, z)(\mathrm{m})$ & & NSR & Velocity $(\mathrm{m} / \mathrm{s})$ & Grain diameter $(\mathrm{m})$ \\
\hline $\begin{array}{l}1 \\
(1.9,1.9,12)\end{array}$ & $\begin{array}{c}2 \\
(1.9,-1.9,12)\end{array}$ & $\begin{array}{c}3 \\
(-1.9,-1.9,12)\end{array}$ & $\begin{array}{c}4 \\
(-1.9,1.9,12)\end{array}$ & 1.8 & 40 & 0.0001 \\
\hline
\end{tabular}

TABLE 6: Comparison between SNCR simulation value and experiment value.

\begin{tabular}{lccc}
\hline Data categories & NO mass flow $\left(\mathrm{mg} / \mathrm{m}^{3}\right)$ & $\mathrm{NH}_{3}$ mass flow $\left(\mathrm{mg} / \mathrm{m}^{3}\right)$ & Denitrification efficiency $(\%)$ \\
\hline Experimental data & 208.09 & 30.21 & 73.57 \\
Simulation data & 187.60 & 32.40 & 74.75 \\
Relative error & $9.85 \%$ & $7.25 \%$ & 1.60 \\
\hline
\end{tabular}

\section{Conclusion}

SNCR numerical study was carried out based on a $2500 \mathrm{t} / \mathrm{d}$ new type dry cement kiln decomposing furnace in a plant of Hunan Province. The research conclusions are as follows:

(1) The molar ratio of ammonia to nitrogen has a significant effect on the NO reduction in the decomposing furnace: as the molar ratio of ammonia to nitrogen increases, the concentration of $\mathrm{NO}$ at the outlet of the decomposing furnace decreases and the overall denitrification efficiency increases, but the concentration of $\mathrm{NH}_{3}$ escaping also increases synchronously. Under the research conditions, a better ammonia-nitrogen molar ratio was 1.8 .

(2) The molar ratio of ammonia to nitrogen has a significant effect on the NO reduction in the decomposing furnace: as the molar ratio of ammonia to nitrogen increases, the concentration of $\mathrm{NO}$ at the outlet of the decomposing furnace decreases and the overall denitrification efficiency increases, but the concentration of $\mathrm{NH}_{3}$ escaping also increases synchronously. Under the research conditions, a better ammonia-nitrogen molar ratio was 1.8.

(3) With the increase of the spray velocity of urea solution, the mixture of urea solution and main flue gas is more uniform. Meanwhile, the evaporation process of urea solution is shorter and the denitrification efficiency is further improved. Under the study conditions, the better urea solution injection velocity was $40 \mathrm{~m} / \mathrm{s}$.

(4) Under the study conditions, the optimal process parameters are as follows: the injection height of urea solution is $12 \mathrm{~m}$, the NSR is 1.8 , and the spray velocity of urea solution is $40 \mathrm{~m} / \mathrm{s}$. The simulation results under the optimal process parameters are as follows: the NO outlet concentration at the outlet of the decomposing furnace is $187.60 \mathrm{mg} / \mathrm{m}^{3}$, the $\mathrm{NH}_{3}$ escape concentration is $32.40 \mathrm{mg} / \mathrm{m}^{3}$, and the denitrification efficiency is $74.75 \%$.

In this paper, the inlet layout and particle size distribution of the urea solution are set as the same parameters in the simulation. However, according to the practical operation experience of cement plants, the particle size and particle size distribution of urea solution would also have a great impact on SNCR denitrification.

\section{Abbreviation}

SNCR: Selective noncatalytic reduction

SCR: Selective catalytic reduction

CRF: Combustion research facility

CFB: Circulating fluidized bed

NSR: Ammonia-nitrogen molar ratio

EDC: Eddy dissipation conceptual model

Nomenclature

$\rho$ : Density of the gas

$k$ : Turbulent kinetic energy

$\varepsilon$ : Turbulent dissipation velocity

$\mu$ : Molecular viscosity coefficient

$\mu_{t}$ : Turbulent viscosity coefficient

$C$ : Constant term coefficient.

\section{Data Availability}

The experimental data used to support the findings of this study are available from the corresponding author upon request.

\section{Conflicts of Interest}

The authors declare that they have no conflicts of interest.

\section{Acknowledgments}

This work was financially supported by the National Natural Science Foundation of China (51590891), Youth Fund of National Natural Science Foundation of China (51806184), and the Science and Technology Key Project of Chenzhou Municipal (CZ2013163).

\section{References}

[1] China Cement Association, "The 13th five-year development plan of cement industry," Chinese Cement, vol. 27, no. 7 , pp. 7-17, 2017.

[2] J. Wu, G. Liang, D. Hui et al., "Prolonged acid rain facilitates soil organic carbon accumulation in a mature forest in Southern China," Science of The Total Environment, vol. 544, pp. 94-102, 2016. 
[3] Y. Zou, X. J. Deng, D. Zhu et al., "Characteristics of 1 year of observational data of VOCs, $\mathrm{NO}_{\mathrm{x}}$ and $\mathrm{O}_{3}$ at a suburban site in Guangzhou, China," Atmospheric Chemistry and Physics, vol. 15, no. 12, pp. 6625-6636, 2015.

[4] H. C. Lv, W. J. Yang, Z. J. Zhou et al., "Application of selective non-catalytic reduction on a power plant boiler," Proceedings of The Chinese Society for Electrical Engineering, vol. 28, no. 23, pp. 14-19, 2008.

[5] F. Q. Liu, D. X. Yu, J. Q. Wu et al., "Effect of SCR on particulate matter emissions from a coal-fired boiler," Journal of Chemical Industry and Engineering (China), vol. 69, no. 9, pp. 4051-4057, 2018.

[6] S. Zandaryaa, R. Gavasci, F. Lombardi et al., "Nitrogen oxides from waste incineration: control by selective non-catalytic reduction," Chemosphere, vol. 42, no. 5-7, pp. 0-497, 2001.

[7] W. Sang, S. Bae, R. Ah, and K. Done, "NO removal by reducing agents and additives in the selective non-catalytic reduction (SNCR) process," Chemosphere, vol. 65, no. 1, pp. 170-175, 2006.

[8] M. Shiva, B. Jan, and P. K. Jonathan, " $\mathrm{NO}_{\mathrm{x}}$ formation and selective non-catalytic reduction (SNCR) in a fluidized bed combustor of biomass," Biomass and Bioenergy, vol. 34, no. 9, pp. 1393-1409, 2010.

[9] P. Gao, C. M. Lu, K. H. Han et al., "NO removal by adding additives in the selective non-catalytic reduction process," Journal of Combustion Science and Technology, vol. 14, no. 4, pp. 333-337, 2008.

[10] D. H. Wang and N. Dong, "A review of urea pyrolysis to produce $\mathrm{NH}_{3}$ used for $\mathrm{NO}_{\mathrm{x}}$ removal," Journal of Chemistry, vol. 2019, Article ID 6853638, 11 pages, 2019.

[11] K. H. Han, C. M. Lu, Y. Z. Wang et al., "Experimental study on de- $\mathrm{NO}_{\mathrm{x}}$ characteristics of selective non-catalytic reduction," Proceedings of The Chinese Society for Electrical Engineering, vol. 28, no. 14, pp. 80-85, 2008.

[12] F. F. Li and S. H. Wu, "Numerical simulation of selective noncatalytic reduction process with turbulence mixting influence," Proceedings of The Chinese Society for Electrical Engineering, vol. 23, pp. 46-52, 2008.

[13] Q. Li, Y. X. Wu, H. R. Yang et al., "Simulation and optimization of SNCR process," Journal of Chemical Industry and Engineering (China), vol. 64, no. 5, pp. 1789-1796, 2013.

[14] S. S. Xu and L. N. Zhang, "Simulation study on the better flue gas velocity of high efficiency and low $\mathrm{NO}_{\mathrm{x}}$ combustion of coal blends in the calciner," Bulletin of The Chinese Ceramic Society, vol. 33, no. 3, pp. 547-552, 2014.

[15] D. H. Wang, X. T. Wang, Y. H. Guo et al., "Influence of OFA nozzle position on $\mathrm{NO}_{\mathrm{x}}$ Emission," Chinese Journal of Power Engineering, vol. 32, no. 7, pp. 523-527, 2012.

[16] G. S. Du, D. C. Wang, L. Li et al., "Simulation of 3-d flow around a van-body truck with RNG $k-\varepsilon$ turbulence model," Journal of Hydrodynamics, vol. 13, no. 4, pp. 98-101, 2004.

[17] M.-L. Zhang and Y.-M. Shen, "Three-dimensional simulation of meandering river based on 3-D RNG $\mathrm{k}-\varepsilon$ turbulence model," Journal of Hydrodynamics, vol. 20, no. 4, pp. 448-455, 2008.

[18] S. X. Mei and J. L. Xie, "Numerical simulation of co-combustion of coal and RDF in coupling with decomposing of calcium carbonate in a precalciner with swirl," Journal of Chemical Industry and Engineering (China), vol. 2, no. 24, pp. 1-9, 2017.

[19] S. X. Mei, J. L. Xie, F. He et al., "Numerical simulations in double-sprayed precalciner by changing the location of raw meal inlets," Journal of Wuhan University of Technology, vol. 34, no. 9, pp. 26-30, 2012.
[20] S. S. Xu, H. Wu, F. H. Liu et al., "Simulation study on the optimum bottom cone inlet diameter of coal blends combustion in the precalciner," Bulletin of The Chinese Ceramic Society, vol. 35, no. 8, pp. 2383-2388, 2016. 